\title{
OBSERVATION ON THE FOUNDATION OF KINETIC THEORY OF GASES
}

\author{
U. BASU \\ S.N. Bose Institute of Physical Sciences \\ Calcutta University \\ 92, Acharya Prafulla Chandra Road \\ Calcutta-700009 \\ and \\ M. DUTTA \\ Department of Applied Mathematics and Centre of \\ Advanced Study in Applied Mathematics \\ Calcutta University \\ 92, Acharya Prafu1la Chandra Road \\ Calcutta-700009
}

(Received December 1, 1979)

ABSTRACT. This paper deals with the study of the mathematical foundation of the Kinetic theory of gases. The significance of the Boltzmann model for a system of particles treated by classical mechanics is briefly explained. An apparent, but Inherent difficulty in this model is pointed out.

KEY WORDS AND PHRASES. Mathematical foundation, Model, classical mechanical particle system.

AMS (MOS) SUBJECT CLASSIFICATION (1979) CODES. 82-02.

1. BOLTZMANN MODEL IN KINETIC THEORY.

For a quantitative explanation of the behaviour of fluids, the basic equation of kinetic theory as derived by Boltzmann [1] is given by 


$$
\begin{aligned}
& \frac{\partial f}{\partial t}(\underset{\sim}{\mathfrak{r}}, \underset{\sim}{\mathrm{v}}, \mathrm{t})+\left(\underset{\sim}{\mathrm{v}} \cdot \operatorname{grad}_{\underset{\sim}{f}} f\right)+\left(\underset{\sim}{\mathrm{F}} \cdot \operatorname{grad}_{\underset{\sim}{\mathrm{v}}} f\right)
\end{aligned}
$$

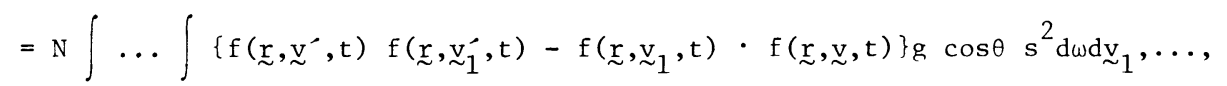

where $\mathrm{N}$ is the number of gas-molecules in a closed volume $V, F(\underset{\sim}{r}, \underset{\sim}{v}, t)$ is the distribution function of the molecules, $\underset{\sim}{\mathrm{F}}$ is the external force on the gas-molecules, $\mathrm{g}=\underset{\sim}{\mathrm{v}}-{\underset{\sim}{\mathrm{V}}}_{1}$ is the relative velocity of the molecule moving with velocity $\underset{\sim}{\mathrm{v}}$ with respect to the other moving with velocity ${\underset{\sim}{1}}_{1}, s^{2} \mathrm{~d} \omega$ is the surface element on the surface of the former molecule subtending a solid angle d $\omega$ at its center, and $\sigma$ is the angle between the normal $\underset{\sim}{r}$ to the surface-element and the direction of relative velocity. $\quad \underset{\sim}{v}$ and $\underset{\sim}{v_{1}}$ are such that after the collision, the former will have velocity $\underset{\sim}{\mathrm{v}}$.

For calculation of the terms indicating the effects of collision on the right hand side of equation (1.1), Boltzmann considered the rigid volume of each particle. For calculation of the terms of the left hand side of (1.1) indicating the effect due to velocity, the constituents are treated as simple particles and fluxes due to the continuous change in coordinates and in velocities are taken into account. Thus, there are some apparent paradoxial features in the model introduced by Boltzmann. The mathematical system of Boltzmann is a system of particles of classical mechanics. So, for the clarification of the above, the mathematical foundation of the classical mechanics of a system of particles is useful and so its basic postulates and some relevant analysis are presented here.

2. MODEL OF A CLASSICAL MECHANICAL PARTICLE SYSTEM.

A classical mechanical particle system is represented by $\left\{\mathrm{P}, \mathrm{T}, \mathrm{E}_{3}, \underset{\sim}{\mathrm{r}}: \mathrm{P} \times \mathrm{T} \rightarrow \mathrm{E}_{3}\right.$, $\left.\mathrm{m}: \mathrm{P} \rightarrow \mathrm{R}_{1}, \mathrm{j} \mathcal{S}\right\}$, if and only if it satisfies the following postulates $[2,3,4]$.

(i) POSTULATE ON EXISTENCE. There exists a system of particles indicated by $\mathrm{P}=\left\{\mathrm{p}_{i}\right\} \neq \emptyset$, where $\mathrm{p}_{i}$ is called a particle and $\mathrm{i}=1,2, \ldots, \mathrm{n}$.

(ii) POSTULATE OF TIME. There exists $\mathrm{T}=\{\mathrm{t}\}=\mathrm{I}_{\mathrm{ab}} \subset \mathrm{R}_{1}, \mathrm{I}_{\mathrm{ab}}$ is an interval (open, semi-open, or closed) where the end points a and b; may be infinite and $t$ refers to an instant of time.

(iii) POSTULATE OF SPACE. In classical mechanics, the physical space is isomorphic to $\mathrm{E}_{3}$. 
(iv) POSTULATE OF KINEMATICS. There exists a mapping $\underset{\sim}{\mathrm{r}}$ such that $\underset{\sim}{\mathrm{r}}: \quad \mathrm{P} \times \mathrm{T} \rightarrow \mathrm{E}_{3}$, where $\underset{\sim}{r}$ is an one to one mapping; $\underset{\sim}{r}\left(p_{i}, t\right)$ as a single valued function of $p_{i}$ implies the position of $\mathrm{p}_{i}$ at time $t$. The existence of an inverse function is equivalent to the principle of impenetrability of matter. As a function of $t$, it is bounded in any finite interval of time and has sectionally smooth derivatives. Sectionally smooth means that the entire interval can be divided into a finite number of sections in which $\underset{\sim}{r}\left(\mathrm{p}_{i}, t\right)$ has continuous derivatives with respect to $t$. A finite discontinuity of $\underset{\sim}{\mathfrak{r}}\left(\mathrm{p}_{i}, \mathrm{t}\right)$ corresponds to a collision.

(v) POSTULATE OF GEOMETRY OF MASS. There is an additive mapping $m$ such that $\mathrm{m}: \quad \mathrm{P} \rightarrow \mathrm{R}_{1}$.

(vi) POSTULATE OF FORCE. There exists an $F$ where $F$ is a class of mapping $\underset{\sim}{F}$ such that $\underset{\sim}{\mathrm{F}}: \mathrm{P} \times \mathrm{T} \rightarrow \mathrm{E}_{3}$, then $\underset{\sim}{\mathrm{F}}$ is called the external force. (vii) POSTULATE OF INTERACTION. There is a class of mapping $I=\{\underset{\sim}{I}\}$ such that $\underset{\sim}{I}: \quad P \times P \times T \rightarrow E_{3}$ where $\underset{\sim}{I}\left(p_{i}, P_{j}, t\right)=-I\left(p_{j}, p_{i}, t\right)$, then $\underset{\sim}{I}$ is called the interaction force.

(viii) POSTULATE OF CONNECTION. The postulate of connection is given by the following relation:

$$
m\left(p_{i}\right) \underset{\sim}{\stackrel{r}{\sim}}\left(p_{i}, t\right)=\underset{\sim}{F}\left(p_{i}, t\right)+\sum_{i \neq j} \underset{\sim}{I}\left(p_{i}, p_{j}, t\right) .
$$

NOTE: To introduce the notion of collision in classical mechanics of particles, as notion of consecutiveness is absent in the continuum $E_{3}$, interaction forces $I\left(p_{i}, p_{j}, t\right)$ should be such that

$$
\| \underset{\sim}{I}\left(p_{i}, p_{j}, t\right)|| \rightarrow \infty \text { when }\left|\underset{\sim}{r}\left(p_{i}, t\right)-\underset{\sim}{r}\left(p_{j}, t\right)\right| \rightarrow d_{i j}+0,
$$

where $d_{i j}$ represents a fixed number for particles $p_{i}$ and $p_{j}$, signifying the distance between the centers of the particles $p_{i}$ and $p_{j}$. This idea leads to a minimum distance of approach for each pair of particles.

\section{CONCLUSION.}

From the above discussion, it is clear that the notion of a minimum distance of approach of two particles, which means the existence of rigid exclusion volume, is necessary in the classical mechanics of particles, and so in the Boltzmann model of the kinetic theory of gases. 


\section{REFERENCES}

1. BOLTZMANN, L. Vorlesugen uber Gastheorie, Teil. I, J.A. Barth. Leipzig, 1923.

2. HENKIN, L., SUPPES, P. and TARSKI, A. The Axiomatic Method, edited by Henkin, L., Suppes, P. and Tarski, A., p. 226, North Holland Publishing Company, Amsterdam, 1959.

3. SUPPES, P. Introduction to Logic, D. Van Nostrand, New York, 1958.

4. DUTTA, M. Lecture Notes of 'Foundation of Mechanics', (Unpublished), 1974. 


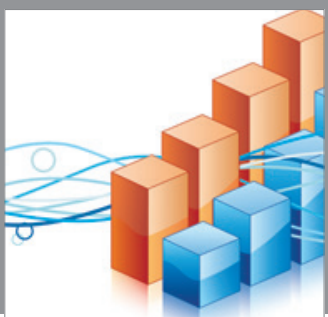

Advances in

Operations Research

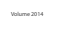

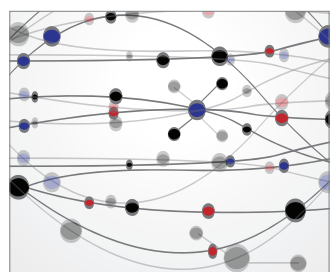

\section{The Scientific} World Journal
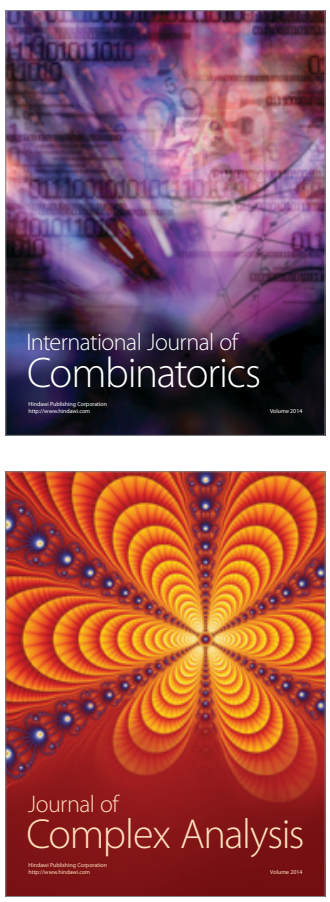

International Journal of

Mathematics and

Mathematical

Sciences
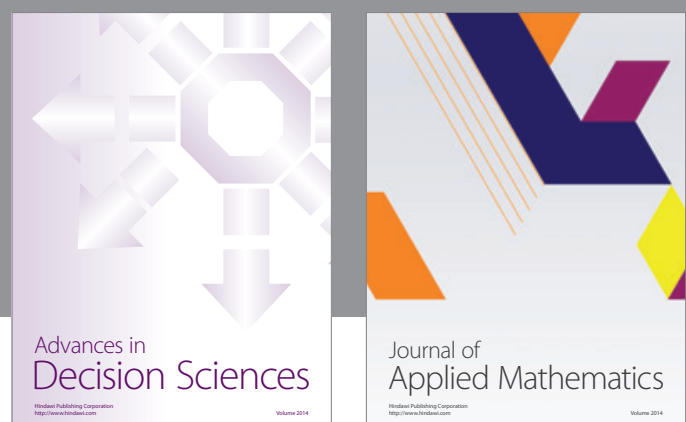

Journal of

Applied Mathematics
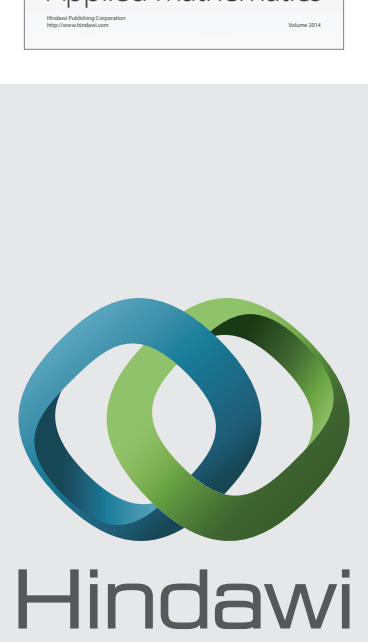

Submit your manuscripts at http://www.hindawi.com
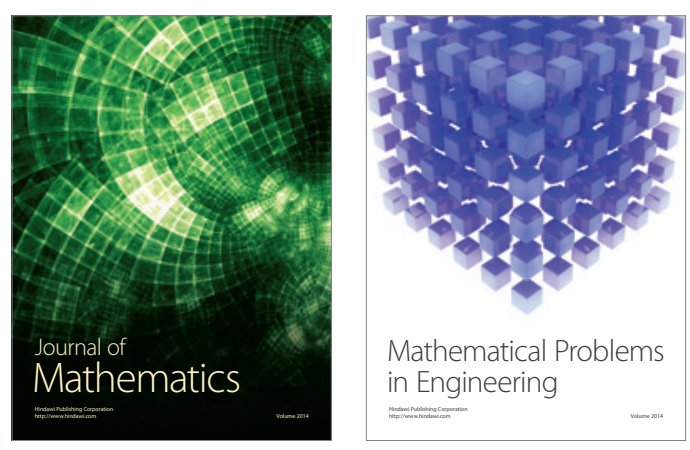

Mathematical Problems in Engineering
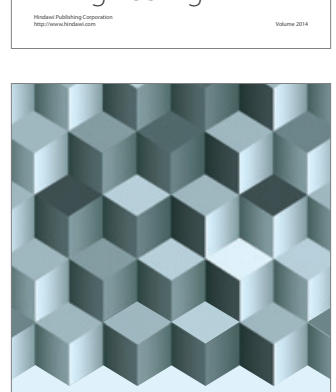

Journal of

Function Spaces
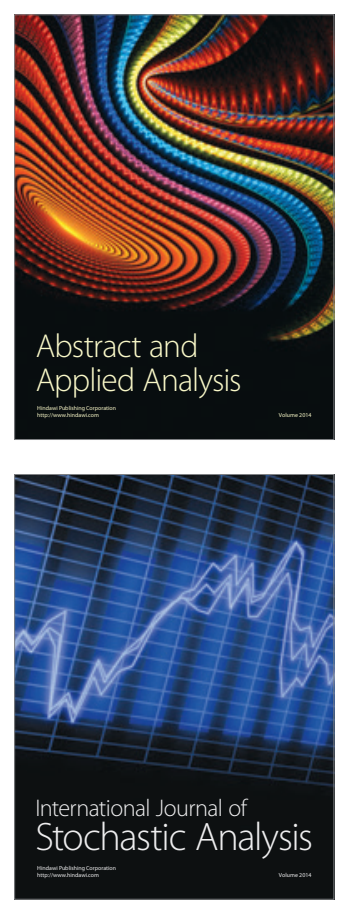

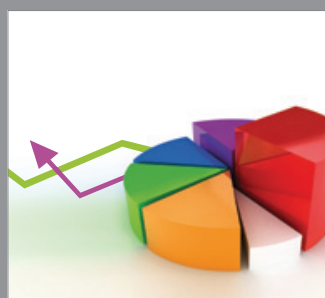

ournal of

Probability and Statistics

Promensencen
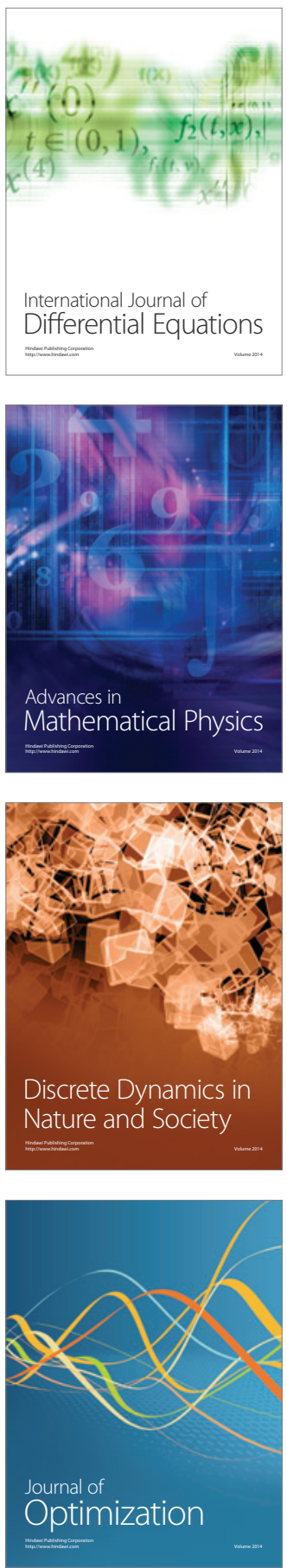